\title{
Measurement of Ultrasonic Velocity in Liquids Using Wireless Technology: Sms
}

\author{
G. K. Singh ${ }^{1}$, S. J. Sharma ${ }^{2}$ and S. Rajagopalan ${ }^{2}$ \\ ${ }^{I}$ Deptt. of Electronics, A.N. College, Anandwan, Warora - 442907 \\ ${ }^{2}$ Deptt. of Electronics, RTM Nagpur University, Nagpur- 440033
}

\begin{abstract}
In the present work, a virtual instrumentation setup utilizing GSM service for remote access via short message service (SMS) for measurements of ultrasonic velocity in liquid and liquid mixture is designed. Communication to the designed instrumentation system is achieved between a mobile phone (server) attached to it and another mobile phone (client). The instrumentation system can be controlled and monitored from anywhere covered by the GSM service by exchanging SMS between server and client under the software control designed in VB6.0. Ultrasonic velocities at various temperatures are measured through SMS between the server and the client mobile phones.
\end{abstract}

KeyWords: virtualinstrument, pulse-echosystem, wirelesscontrol, SMS, ultrasonicvelocityMeasurement, server and client

\section{Introduction:}

Stand-alone/traditional instruments such as oscilloscopes, spectrum analyser, function generators, etc. are expensive and designed to perform one or few specific tasks defined by the vendor. User generally cannot extend or customize them. The knobs and buttons on the instrument, the built-in circuitry and the functions available to the user, are all specific to the nature of the instrument. In addition, special technology and costly components must be developed to build these instruments, making them very expensive and slow to adapt. They do not have any inbuilt computational capability and also require a lot of power [1,2].

Virtual instrumentation $[3,4]$ combines PC with flexible software and a wide variety of measurement and control hardware to create user defined systems to meet exact application needs. User of virtual instrument can change its function at will to suit the wide range of applications. The concept prevailed when microprocessor technology enabled a machine's function to be changed by its software [5]. Recently, most of the computers incorporate all the hardware and software required by the instruments for specific purpose and are fast enough to work in real time. The instrument manufacturer now supplies only specialized subunit and software as a part of virtual instrument. Development in the local area networks (LAN) allows to physically separate the computer portion from the rest of the instrument. With the introduction of some of the latest remote radio communication protocols such as "Bluetooth", the components needn't even be physically connected to each other. Further, using higher speed wireless and internet programming, the information can be processed, controlled, displayed, or distributed anywhere in the world.

In the present work, Multi-Frequency Ultrasonic Pulse-Echo System [6] for ultrasonic velocity measurements in liquids and liquid mixtures, designed and described in our earlier work is controlled remotely and measurements of ultrasonic velocities at different temperatures are carried out with SMS facility of the mobile phone.

\section{Experimental:}

Multi-Frequency Ultrasonic Pulse-Echo setup utilizing GSM service to enable mobile access via short message service (SMS) in order to perform remote measurements of ultrasonic velocity in liquid and liquid mixtures, is shown in Fig. 1.

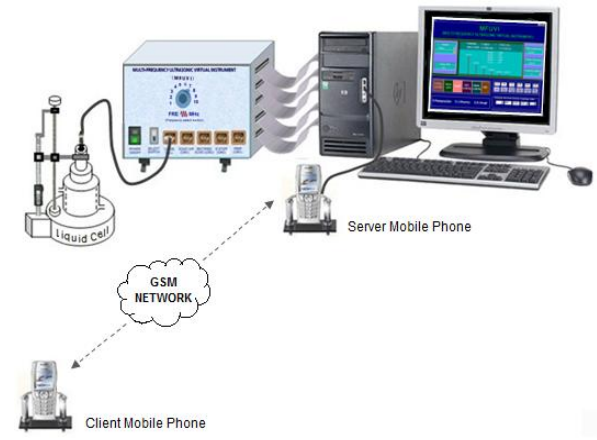

Fig.1: Experimental Setup 
General Server-Client structure is used to carry out measurements remotely with SMS. The Nokia handset is connected to USB port of PC with USB cable and acts as server that sends/receives SMS to/from the client mobile [7]. A control program, including functions (Read SMS, Send SMS, Delete SMS, etc) from Nokia Suite [8], is developed in VB6.0 and uses SDK3.0 [9] to send and receive SMS through server mobile phone to and from the client mobile phone. The Specified Client mobile is allowed to access the experimental system to perform various functions such as measurement and setting of sample temperature, and estimation of ultrasonic velocity in sample under study.

\section{Description:}

Remote control of Multi-Frequency Ultrasonic Pulse-Echo system using SMS for ultrasonic velocity measurements is shown in Fig.2.

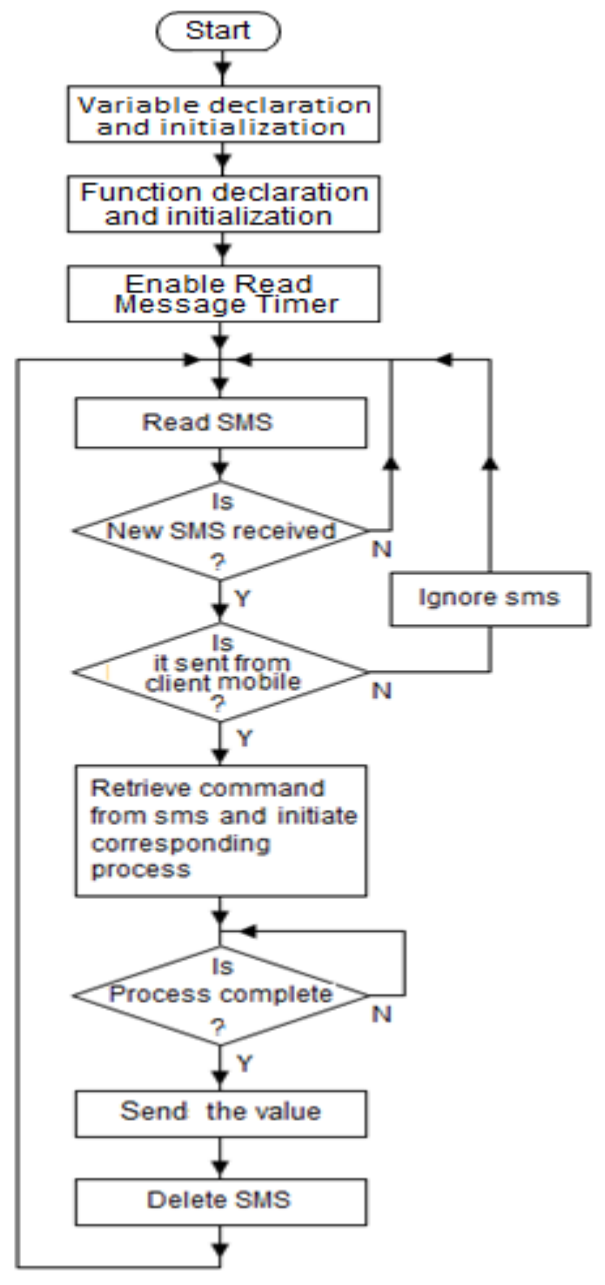

Fig.2: Flowchart of SMS Control of VI

SMS Control program running on server side PC

continuously scans server mobile phone attached to it for any new received SMS and if any new

SMS is received, the SMS Control function verifies whether it is sent from the client mobile phone. If the SMS is sent from the client mobile phone, it reads the SMS and retrieves the command from it, otherwise ignores it. The retrieved command can be one of the commands defined for reading the present temperature of the sample temperature, setting the sample temperature to desired value, or finding ultrasonic velocity at desired temperature.

If retrieved command from SMS sent by client mobile phone, at remote place, is for setting the sample temperature to a desired value, the SMS Control function instructs Software Controlled Thermostat . When desired sample temperature is attained, the SMS Control function acknowledges the client mobile phone by sending SMS automatically. Similarly, if the retrieved command from SMS is for finding the velocity at the desired temperature, the SMS Control function calls Velocity function that starts the process to find velocity, and when process completes it, it sends this value to client mobile phone through SMS. Thus, the user can monitor and observe sample temperature, and find ultrasonic velocity without being present in front of the system. 


\section{Result And Discussion:}

Table-1 shows ultrasonic velocity measured using SMS communication between server and client mobile phones in distilled water and acetonitrile at different temperature.

\section{Conclusion:}

In the present work remote control and monitoring of Multi-Frequency Ultrasonic Pulse-Echo system is attempted using SMS to estimate the ultrasonic velocities at different temperatures using mobile phone. Such a system is found to be very effective, reliable and useful to the researcher to remotely control the parameters of the system and save the values of interest for further analysis or computation. Access to any instrumentation at any remote place can be accomplished. The system developed in the present work is found to work satisfactorily and provides an efficient method for remote experimentation. It also provides a strong platform for collaborative experimentation and e-learning in near future.

Table-1

\begin{tabular}{|c|c|c|c|}
\hline \multirow{4}{*}{ Sample } & $\begin{array}{c}\text { Temp } \\
\left({ }^{\mathbf{0}} \mathbf{C}\right)\end{array}$ & $\begin{array}{c}\text { Measured } \\
\text { Velocity(u) } \\
(\mathbf{m} / \mathbf{s})\end{array}$ & $\begin{array}{c}\text { Lit. Value } \\
(\mathbf{m} / \mathbf{s})\end{array}$ \\
\hline \multirow{4}{*}{$\begin{array}{c}\text { Distilled } \\
\text { Water } \\
\left(\mathrm{H}_{2} \mathrm{O}\right)\end{array}$} & 20 & $1483.129 \pm 6.220$ & $1482.343[10]$ \\
\cline { 2 - 4 } & 25 & $1495.327 \pm 6.317$ & $1496.687[10]$ \\
\cline { 2 - 4 } & 30 & $1509.434 \pm 6.430$ & $1509.127[10]$ \\
\cline { 2 - 4 } & 35 & $1518.026 \pm 6.499$ & $1519.808[10]$ \\
\hline \multirow{4}{*}{$\begin{array}{c}\text { Acetonitrile } \\
\left(\mathrm{C}_{2} \mathrm{H}_{3} \mathrm{~N}\right)\end{array}$} & 20 & $1529.637 \pm 6.592$ & $1528.863[10]$ \\
\cline { 2 - 4 } & 20 & $1313.629 \pm 4.927$ & $1305.000[11]$ \\
\cline { 2 - 4 } & 30 & $1292.407 \pm 4.808$ & $1290.000[11]$ \\
\cline { 2 - 4 } & 35 & $1244.885 \pm 4.681$ & $1264.000[11]$ \\
\cline { 2 - 4 } & 40 & $1232.666 \pm 4.480$ & $1245.000[11]$ \\
\hline \multirow{4}{*}{} & & & $1224.000[11]$ \\
\hline
\end{tabular}

\section{Acknowledgement:}

One of the authors is grateful to Dr. V. D. Bhandakkar, HOD, Deptt. Of Electronics, A.N.College, Warora, for fully cooperating to successful implementation of this work in the Department of Electronics. The author is also thankful to Prof. Milind Despande, HOD, Deptt. Of Physics, A. N. College, Warora, for his logical reasoning needed in present work.

\section{References:}

[1]. Sumathi S. and Surekha P., LabVIEW Based Advanced Instrumentation Systems, Springer, 2007

[2]. Rihan M. and Agarwal A., Virtual Instrumentation For Bio-Medical Applications, Proc. of the 4th National Conference, Bharati Vidyapeeth's Institute of Computer Applications and Management, New Delhi,INDIACom (2010)

[3]. Goldberg H., What is Virtual Instrumentation?, IEEE Instrumentation \& Measurement Magazine, 10-13 (2000)

[4]. Obrenovic Ž., Starcevic D., Jovanov E., Virtual Instrumentation, www.scribd.com /doc/38490061/Virtual-Instrumentation

[5]. Santori M., An instrument that isn't really, IEEE Spectrum, 27(8), 36 -39 (1990)

[6]. Singh G. K., Pendse V. M., Sharma S. J. and Rajagopalan S., Development of Multi-Frequency Pulse-Echo System, (communicated)

[7]. Singh G. K., Pendse V. M., Sharma S. J. and Rajagopalan S., Design of Mobile Phone Based Precise Temperature Controller, National Symposium on Instrumentation (NSI- 32) at K.S.Rangasamy College of Technology, Tiruchengole, Tamil Nadu, 416-417 (2007)

[8] Nokia PC Connectivity SDK 3.0 Component Library Reference, For Nokia Phones, www.forum.nokia.com/tools

[9]. Nokia PC Connectivity SDK 3.0 for Nokia Phones, www.forum.nokia.com /tools

[10]. Del Grosso V.A. and Mader C.W., Speed of Sound in Pure Water, J. Acoust. Soc.Am., 52(5b), 1442-1446 (1972)

[11]. SOS (Speed of sound) Data for Methanol, Ethanol, Acetone, Acetonitrile, The DDBST (DORTMUND DATA BANK SOFTWARE \& SEPARATION TECHNOLOGY), www.ddbondline.ddbst.de 